\title{
Beyond the Ecology of Concrete Sausages
}

\author{
SASA ZIVKOVIC \& LESLIE LOK
}

Cornell University

With the advancement of full scale $3 d$ printing technology, industrialized building construction is rapidly moving towards a highly process-idiosyncratic and expressionist architecture of material sausages. Drawing connections between local vernacular (ancient modern) earth construction techniques and automated additive manufacturing strategies, this paper explores the potential for $3 d$ printed architecture across the Americas, dissecting the technology's ecological advantages and architectural possibilities in the process.

\section{ADDITIVE MANUFACTURING: OVERVIEW AND POTENTIAL}

The advance of open-source desktop 3d printers such as the RepRap ${ }^{1}$ (Replicating Rapid-prototyper), conceived as a self-replicating and small-scale home manufacturing device, has fostered a rapid revolution and evolution of additive manufacturing. In architecture, rapid prototyping has since become an important tool for translating complex digital geometries into small physical models. Despite limitations in speed, resolution, and copyright ${ }^{2}$, as well as difficulties with the development of adequate material mixtures, full scale $3 \mathrm{~d}$ printing at the building and component scale has recently become anubiquitous research topic in architecture schools and for building industry across the globe. The technology offers advantages over other industrialized techniques such as standard precast concrete fabrication by allowing for formal variability and geometric flexibility. In Fabricated: The New World of 3D Printing ${ }^{3}$ Hod Lipson and Melba Kurman outline the multiple opportunities and potential paradigm-shifts of the technology including multi-material printing and material design, ease of digital-physical translations, affinity towards mass customization, non-assembly of components in integrated systems, or the ability to manufacture locally on site. Those advantages will likely ensure that additive manufacturing processes become further ingrained in the design and making of architecture.

In 2016, Dubai has recognized the possibilities and importance of 3d printing for the development of its building sector and devised an agenda with the goal to $3 \mathrm{~d}$ print 25 percent of its buildings by the year of $2030 .{ }^{4}$ In the currently unfolding transformation from the Third

Industrial Revolution to the Forth, 3d printing will become a key technology which allows for a much stronger hybridization of the physical and digital realms. The possibilities seem endless; we are currently merely scratching the surface of the possible.

\section{MATERIAL ECOLOGY: CONCRETE SAUSAGES AND BEYOND}

$3 \mathrm{~d}$ printing is sausage architecture. During the $3 \mathrm{~d}$ printing process, material is extruded through a nozzle, forming linear distributions of matter. Material sausages are stacked in layers by either a three axis gantry system or a multi-axis robotic arm (as well as combinations of the two). The material assemblies have to be self-adhering, self-supporting, and fast-curing. Before printing can occur, digital geometries are translated into $\mathrm{G}$-code which determines the tool path of the machine. This rather simple machine process yields the potential for extraordinarily complex parts and geometries.

While rapid prototyping is primarily based on printing with plastics such as PLA and ABS, full scale printing at the building scale focuses on concrete as the main structural material. With the help of superplasticisers and retarders, concrete can be engineered to become printable. It is potentially extrudable, self-supporting, self-adhesive, and workable, it has a long enough open time to be processed as well as sufficient compressive strength for building applications. ${ }^{5}$ It is the current default material for the development of full scale $3 \mathrm{~d}$ printing

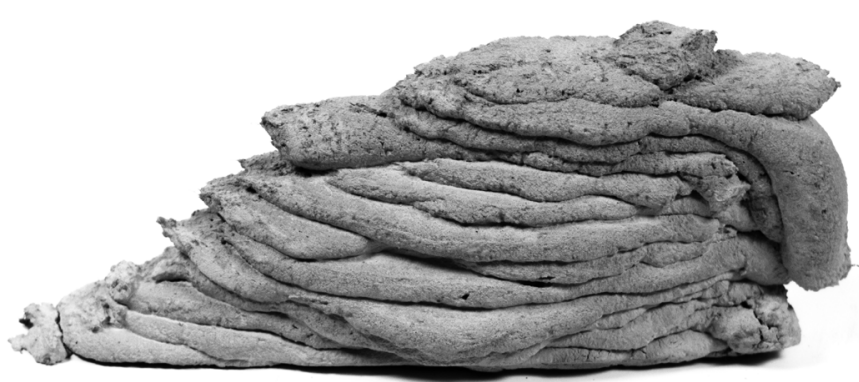

Figure 1: Sausage aesthetics: Initial concrete 3d test print for Additive Architectural Elements | Photograph by HANNAH 


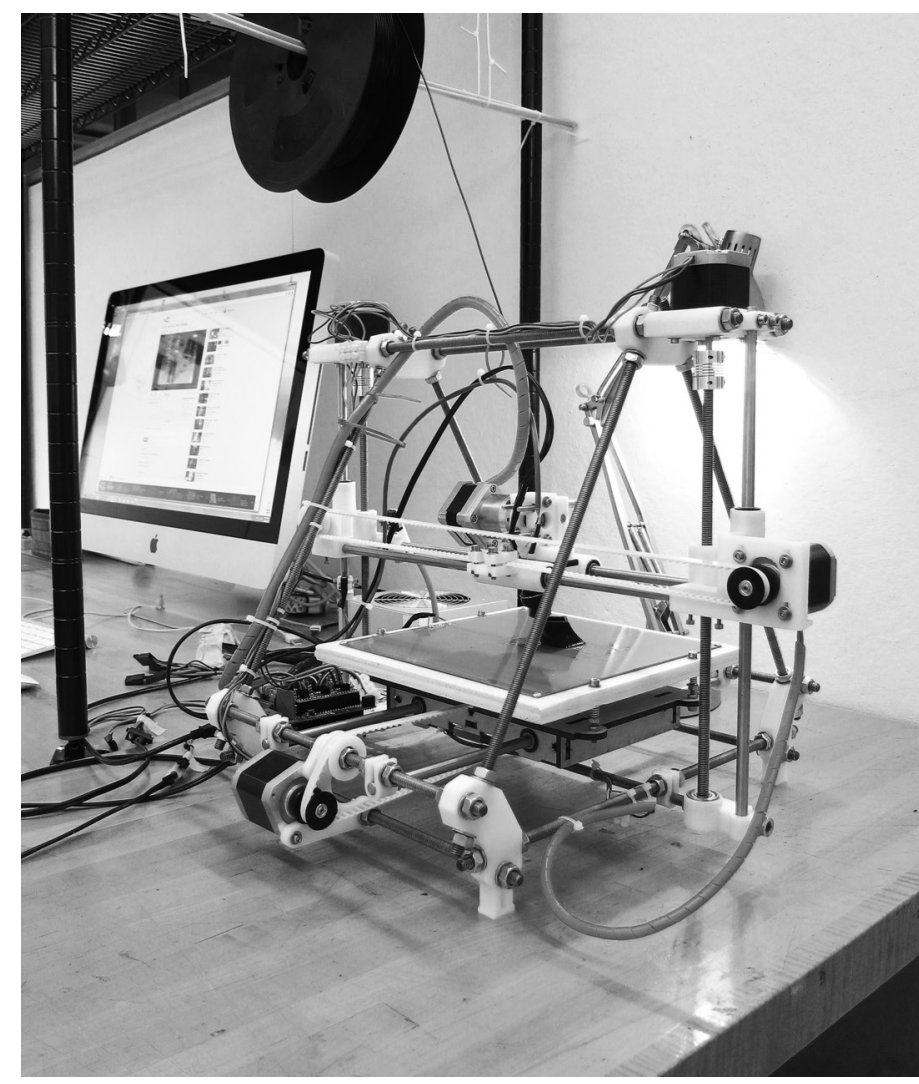

Figure 2: RepRap 3d printer and large scale Daedalus 3d printer (constructed as part of a Cornell University Option Studio) | Photographs by the authors

protocols. However, there are considerable disadvantages for the use of concrete as a construction material. Concrete has various negative effects on global climate, local environments, and ecosystems. ${ }^{6}$ Its production process is very high in energy and considerably contributes to global $\mathrm{CO} 2$ emissions, water pollution, as well as sand shortage. ${ }^{7}$ Yet, concrete is fast, cheap, and easily operates at an industrial scale. It has become the default modern material for architecture and urbanism across the globe.

In $3 d$ printing, the ubiquitous-ness of concrete is paradoxically one of its potential ecological advantages. As a resource that can be found anywhere on earth - even in the most remote places - it can be re-used as aggregate for $3 \mathrm{~d}$ printing material mixtures, drastically improving its ecological footprint. In additive manufacturing, old concrete can be recycled and reused to form environmentally sensible sausages. Various research projects such as the TU Eindhoven 3d Print Research Initiative are developing strategies to increase concrete recycling rates to up to $70 \% .{ }^{8}$ Besides the recycling of locally available old concrete structures, $3 \mathrm{~d}$ printers can print with other readily available local material: soil, clay, local gravel as aggregate, or recycled plastic. All those materials have a very low ecological footprint and can be adapted to become printable. There is an opportunity to move beyond new, un-recycled concrete as a default material for full scale additive manufacturing. Moving forward, research has to progress beyond concrete sausages.

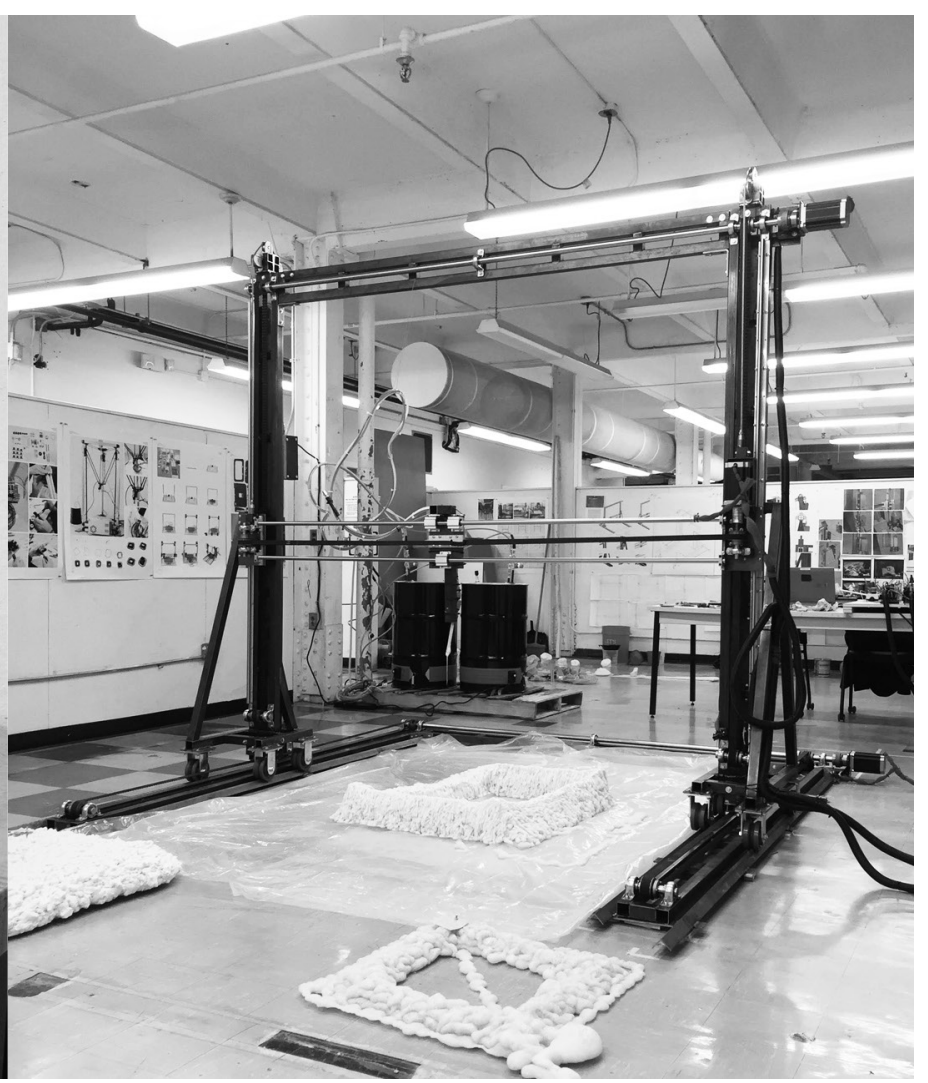

HYPER-LOCAL MANUFACTURING: RETHINKING THE SCALE, SCOPE, AND “OPERATIVE ECOSYSTEM" OF THE FACTORY

The potential for local manufacturing is one of the tremendous advantages of $3 \mathrm{~d}$ printing. Gantry systems and robotic arms are transportable and can be deployed directly to the building site. The factory can adapt to its local context by using readily available soil based materials to print buildings. Compared to precast construction as well as other building techniques this approach has multiple advantages. Transportation of materials can be highly reduced in this process. It is no longer required to move large quantities of physical mass from the site of the factory to the site of construction. Breaking down massive conglomerations of industry and moving towards distributed manufacturing has ecological as well as social repercussions. As the technology is increasingly open-sourced and decreased in scale and cost, more individuals can become owners of advanced fabrication facilities. ${ }^{9}$ Substituting even only one third of current precast concrete construction techniques for advanced and distributed soil or recycled concrete construction would have vast ecological and social impacts.

Local additive manufacturing strategies have also been researched by NASA with the conclusion that the technology is the most likely scenario to construct extraterrestrial habitats. ${ }^{10}$ It reduces transportation cost and works in remote areas. The economic ecology of extraterrestrial space projects dictates using the most efficient construction method. The fundamental principles of this NASA ecology and resourcefulness with a focus on the use of local resources apply to our planet as well. 
HISTORY OF VERNACULAR EARTH CONSTRUCTION, SOIL TYPES, AND TRANS-AMERICAN POSSIBILITIES

Building with earth is one of the world's oldest and most widely used construction methods. It is estimated that up to three billion people live in structures made from earthen materials. ${ }^{11}$ This figure includes adobe brick and other types of common soil construction methods. Soils are decomposed rocks with differing grain sizes of gravel, sand, silt, and clay. Distinct proportions of these basic elements mixed with biological deposits result in a wide array of soil types. Archeological evidence for earthen houses and residences is often rare. Due to natural erosion which significantly reduces archeological evidence, few ancient structures at the residential scale can be found today.

Yet, despite a shortage of abundant evidence, it can be assumed that building with earth has a long tradition and history in both North and South America because buildable soil as a natural resource is readily available throughout the continent. Desert soil, laterite (tropical red earth), and mountain soil which are all highly prevalent in South America and the southwest of North America are well suited for building and construction. Laterites are prominent in Amazonia, Brazil, Columbia, and the North Coast of South America. Where black earth is prevalent in Africa, Argentina, and the Western half of South India, it is extensively used for construction purposes. Wattle and daub construction is often applied where timber and wood are accessible in addition to suitable types of soil. Desert soils with higher sand ratios are prevalent in the North American south-west. They can be mixed with water and stabilized with lime and bitumen to produce adobe bricks. $^{12}$

Across the Americas, a wide range of earth construction techniques emerged in areas with soil that is suitable for construction. Based on the unique properties of local soil types, different techniques developed in different areas. This paper examines the types of methods which are most similar to current $3 \mathrm{~d}$ printing processes in order to foster a productive exchange between new and ancient building technology. Researched techniques include puddled adobe, rammed earth, superadobe, and wattle and daub construction. There are considerable similarities between the ancient methods and current additive manufacturing processes. Based on a similar logic of structure and material deposition, the main difference is that current processes are highly automated and materials are engineered more precisely with various additives. Earth construction is moving towards automated processes which gives architects the opportunity to reimagine how to build with soil in the future and learn from the craft of past architectures.

\section{PUDDLED ADOBE}

Puddled adobe construction is the process in which wet loam - a fertile mixture of sand, silt, and clay that contains some humus - is used in building applications without further refinement. In this manual process, builders apply layer upon layer of wet loam to erect a structure. The technique requires no tools and there is no additional reinforcement in most structures. Puddled adobe precedents can be found in Africa, Asia, Europe, and the Americas. Small buildings are better suited for this type of construction because the shrinkage of the material in the drying process often causes cracks in large houses, leading to structural problems and time-consuming repairs. In buildings where wet loam is used as the only material for construction, structures have to be self-supporting, resulting in round floor plans and dome shaped roofs. ${ }^{13}$ This can be observed at Huápoca, an archaeological site in the northern Mexican state of Chihuahua. ${ }^{14}$

One of the great advantages of puddled adobe construction is that the material can be formed into any shape with very little effort. Wet earth allows for easy shaping of floor plans as well as integration of seating elements and other types of furniture (niches, fireplaces, etc.). Puddled adobe is often mistaken as molded brick architecture because the drying process produces cracking patterns reminiscent of brick

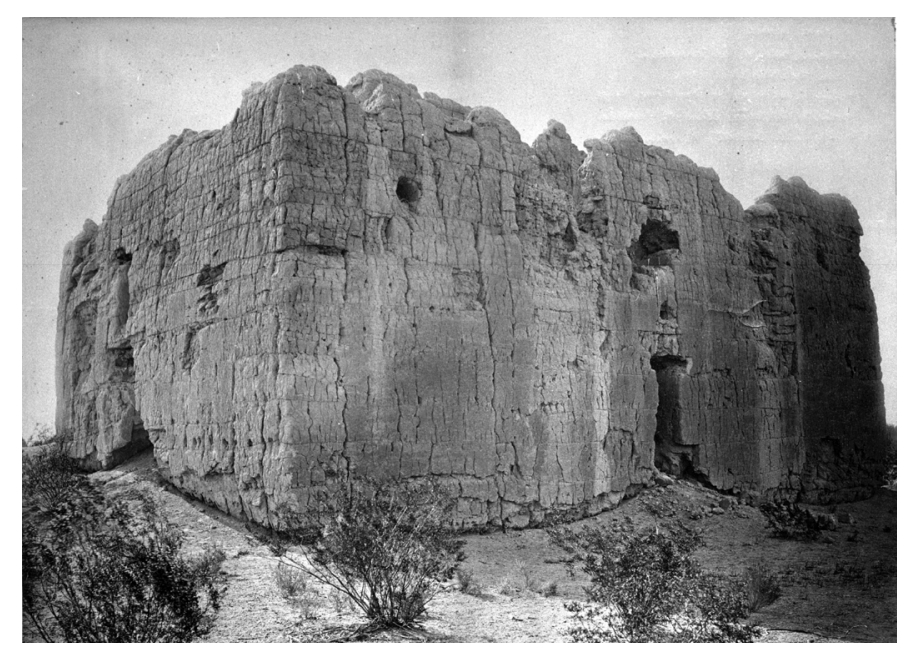

Figure 3: Large scale puddled adobe architecture: West wall of the Casa Grande ca. 1880 | Photographer unknown

construction. ${ }^{15}$ Sometimes such types of earth construction last for centuries. The Casa Grande in Arizona (between 700 - $1450 \mathrm{CE})^{16}$, for example, was build in puddled adobe using a specific type of local soil called Caliche which has properties similar to concrete. Caliche as a mineral deposit of gravel, sand, and nitrates is also found in dry areas of South America. With the right type of soil, building with puddled adobe does not only mean to build small: the Casa Grande (The Big House) is a four story structure. The walls of Casa Grande are up to four feet thick at the base in order to support the loads of the upper stories. Entire cities, such as the Casas Grandes in Mexico (1350 CE / known as Paquimé) have been built using puddled adobe techniques. ${ }^{17}$

With its single material strategy and lack of reinforcement, puddled adobe is similar to the most primitive of large scale $3 \mathrm{~d}$ printing processes which use a single material like concrete for construction. Stacking materials one layer at a time produces un-reinforced simple structures such as explored by the IAAC Mini-builders project. ${ }^{18}$ In such scenarios, the machine allows for increased precision, repeatability, higher resolution, and more complex geometrical operations. The $3 \mathrm{~d}$ printer enables formerly unthinkable propositions, such as industrialized puddled-adobe type architecture. 

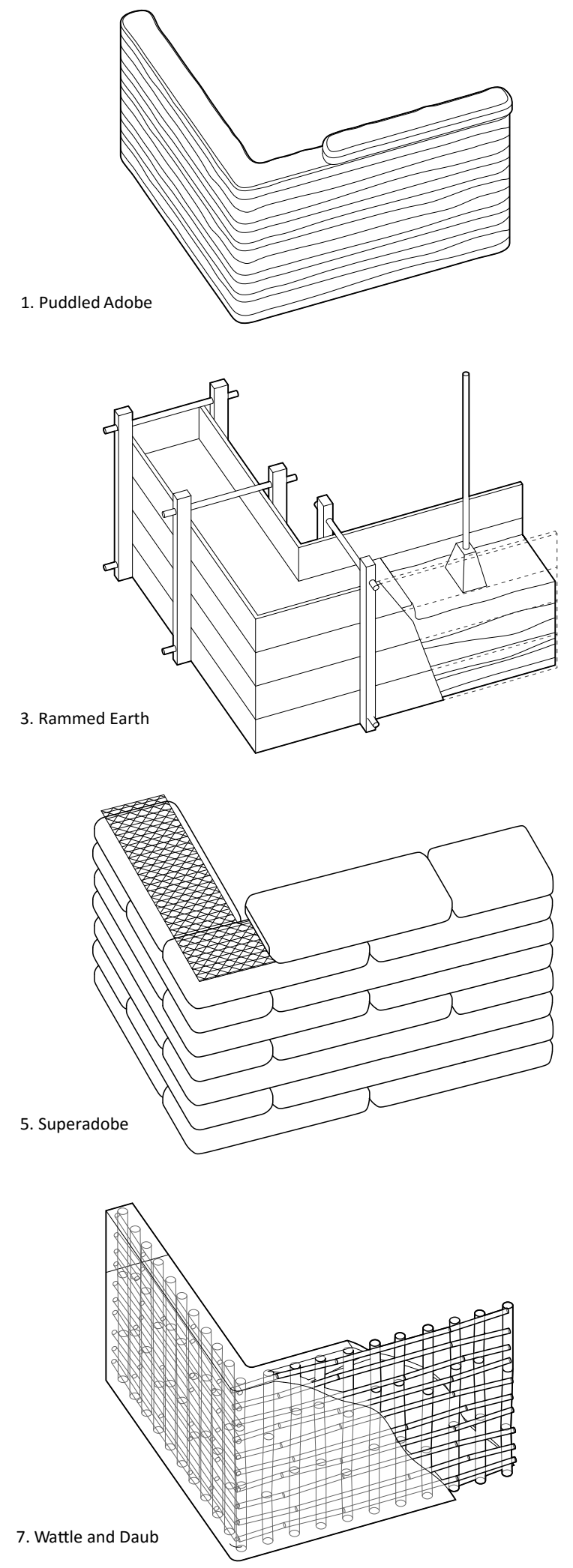
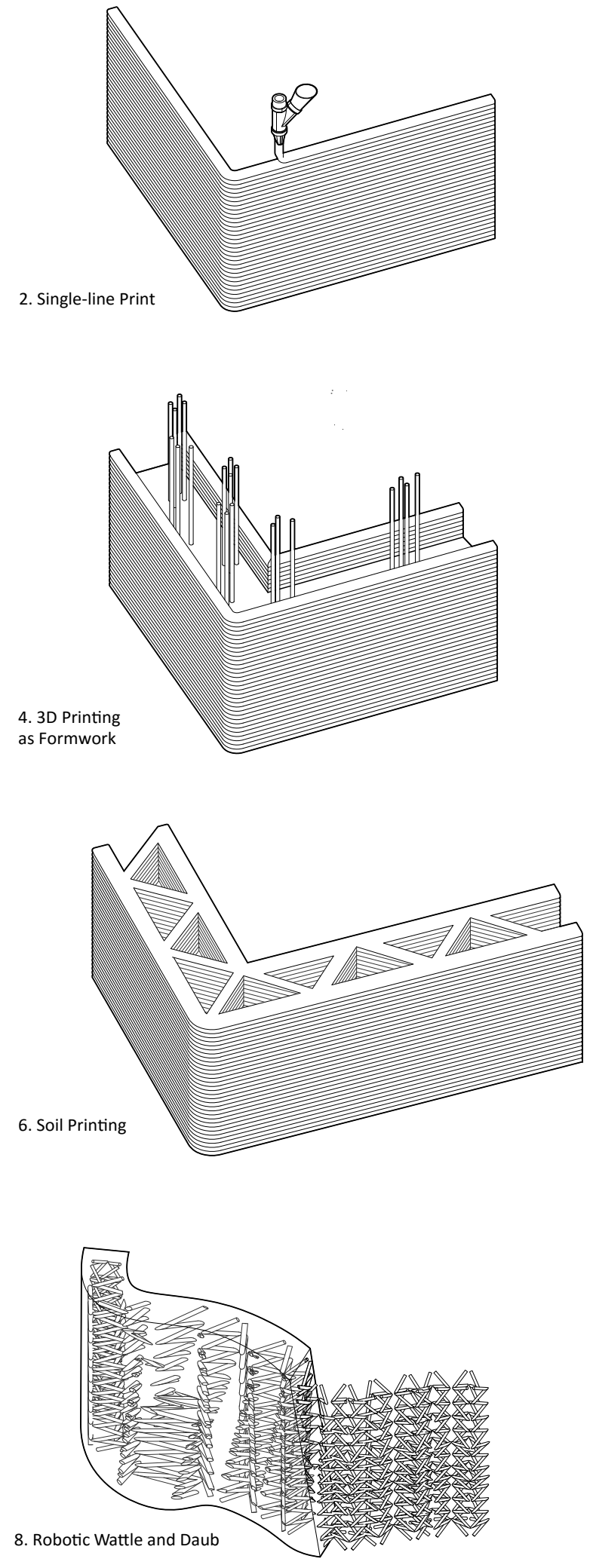

Figure 4: Diagram comparing common earth building techniques with current 3d printing processes: Puddled adobe and single line printing (1) \& (2), rammed Earth and formwork 3d printing (3) \& (4), superadobe and soil printing (5) \& (6), wattle-daub and mesh printing (7) \& (8) | Drawings by the authors 


\section{RAMMED EARTH}

Rammed Earth is a building technique which uses formwork in order produce structural walls with much higher compressive strength than puddled adobe. Archeological evidence suggest that rammed earth construction dates back to as far as 5000 BCE. ${ }^{19}$ In the building process, wet soil is deposited into wooden formwork and then compressed manually with ramming tools. Wet layers are up to five inches thick and get compacted significantly based on the type of soil used. The formwork is either held apart by connecting spacers or bracketed on the exterior of the wall. This approach is very similar to current cast-in-place concrete construction techniques and has multiple benefits: walls are stronger, are less prone to erosion, and there is considerably less shrinkage. Similar to puddled adobe, rammed earth creates its own layered architectural expression and tectonics. It has become a popular revived construction technique in recent years due to its various environmental advantages, benefits for interior climatic conditions, as well as its characteristic aesthetics.

The ruins of Chan Chan (900 - 1470 CE), the largest city in PreColumbian America, bear evidence of the importance of rammed earth construction in South America. ${ }^{20}$ Located in the northern Peruvian region of La Libertadand decorated with elaborate ornamentation, the city is built entirely from earth, its massive walls having resisted erosion for centuries. The sophisticated structures for the ruling royal class are highly intricate pieces of architecture that expose the spatial and cultural potential of earth building.

In current 3d printing processes, formwork still plays an important structural role as the machine does not print the structure itself but essentially constructs its formwork. Walls are built in a step-by-step process: first, the outer layers of the wall are printed either as a single line print boundary or with additional cross connections for stability reasons. In a second step the wall is later infilled with additional concrete and steel reinforcement. This process is very similar to today's precast concrete element fabrication, except that the formwork can vary from one print to the next, allowing for a large range of mass-customized building components. Formwork-based $3 \mathrm{~d}$ printing has been developed by Behrokh Khoshnevis at USC ${ }^{21}$ and is also used by companies such as WinSun ${ }^{22}$ in China.

\section{EARTHBAG AND SUPERADOBE}

Superadobe or earth bag construction is a method of building derived from the construction logic of temporary military architectures in which bags filled with sand or soil are used to erect shelters or bunkers for protection. Superadobe is a patented low-tech economical residential building method which was relatively recently developed/refined by architect Nader Khalili of the California Institute of Earth Art and Architecture. ${ }^{23}$

In this technique, fabric bags are filled with soil and then stacked upon each other to form walls. In order to ensure that layers are stable, strands of barbed wire are placed in between the layers which also gives additional structural stability in earthquakes. To create a roof, successive layers corbel inward as they rise, forming a dome in the process. The soil mixtures used in earth bag construction vary based on context, however, almost all soil types can be used for this method of building. For this reason, as well as its economic advantages, superadobe has been used in the construction of semi-temporary emergency shelters and disaster relief projects worldwide.

Different in methodology but identical in material, projects like the WASP Delta Printer ${ }^{24}$ explore materials similar to superadobe structures. $3 \mathrm{~d}$ printing allow the possibility of precision soil building without the use of fabric containers. Using a large scale Delta printer with a print bed of $12 \times 12 \times 12$ meters, it is possible to build full scale structures in one print.

\section{WATTLE AND DAUB}

In wattle and daub construction, wet loam and earth are mixed with straw or other types of fibers and in-filled in skeleton structures made of woven wood sticks or branches. It is an ancient vernacular construction technique widely used in the Brazilian Amazon as well as other parts of the world. It is believed that wattle and daub construction predates all other earth building techniques. ${ }^{25}$ In the simple process, earth, wood, and straw are collected in the immediate surroundings of the building site. Then a lattice of wood is erected, often with stronger polls at the edges of the building. After the wooden framework is constructed, the earth and clay are prepared by mixing with water until the desired consistency is achieved. In a final step, the mixture is applied to the wooden framework and smoothed out by hand or with a spatula. Like all earthen structures, the walls can be painted in order to increase waterproofing and reduce maintenance.

In northeast Brazil, earth, chalk, lime and gravel are used as raw materials for wattle and daub construction in small scale residential buildings. Here, the special soil mixture does not require the use of additional fibrous components in its execution. ${ }^{26}$ Advantages of wattle and daub construction are the use of readily available local materials as well as relative simplicity of building process. It is a fast and easy method to fill in large structures such as the German Fachwerkhaus.

Similar strategies to wattle and daub construction have recently also emerged in 3d Printing. The project Mesh Mould by Gramzio Kohler from ETH Zurich ${ }^{27}$ utilizes a large scale robotic arm to print variable mesh scaffoldings that get infilled with a shotcrete type cement. Branch Technology from Tennessee ${ }^{28}$ has developed a similar process for industrialized building construction. Both methods use ABS or PLA based filament print heads to build intricate scaffolding structures that vary in density which in turn changes the structure's ability to hold concrete. Architecturally, the automated method yields lots of potential but has yet to be explored beyond the component scale.

\section{ARCHITECTURAL IMPLICATIONS: FORM AND MATERIAL DESIGN INTELLIGENCE}

Architectural and disciplinary implications of a paradigm shift towards additive manufacturing are vast. In ground-up layered 


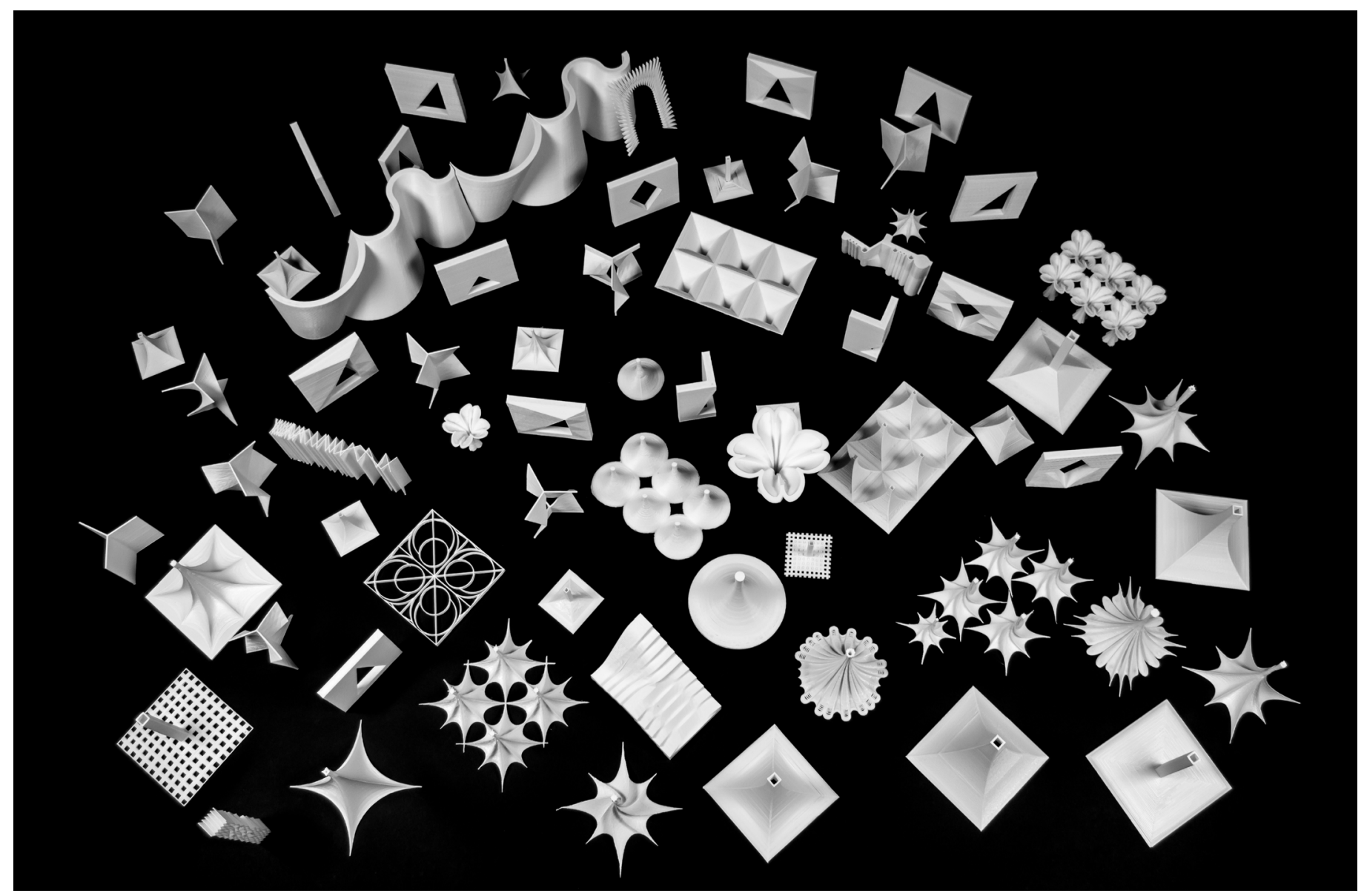

Figure 5: PLA 3d prints of small scale additive architectural element tests | Photograph by HANNAH

processes, structural considerations dictate certain formal strategies. A 3d printer cannot print just anything, it has to follow specific rules in order to successfully erect a structure. Those rules change based on scale and the material used in printing.

Additive manufacturing has its very own and highly idiosyncratic architectural tectonics. While there are constraints, there are also massive opportunities. A recent project called Additive Architectural Elements by $\mathrm{HANNAH}^{29}$ explores architectural opportunities of $3 \mathrm{~d}$ printing. The investigation aims to develop architectural strategies for use in current industrial scale $3 \mathrm{~d}$ printing processes - the assumption being that the technology will eventually evolve to include multi-material printing, non-layered printing, or printing on site among others. However, rather than focusing on the technical development of $3 \mathrm{~d}$ printing technology, this project operates consciously within the status-quo, researching a paradigm-shift that has already occurred but never fully and consequentially been explored architecturally.

In a $3 \mathrm{~d}$ printed structure, all common architectural motifs and building components have to be re-thought to fit the logic of layered construction. For example, a concrete printer cannot print in midair, therefore, printing a rectilinear window opening becomes an insurmountable task. Rather than changing the process (stopping the machine to insert a beam), we believe that shortcomings become opportunities for design: as the printer is able to incrementally cantilever, a logical consequence is for the window to become a triangular corbelled arch. Seemingly advanced technology suddenly connects to obsolete and archaic architectural strategies. Other investigated elements utilize a manipulation of printing direction (printing upside-down or printing in section) in order to overcome printing deficiencies, g-code manipulation for smart material deposit, or manipulations of geometries for structural reasons related to the fabrication process. The $3 \mathrm{~d}$ printer - a machine which has long been characterized as characterless due to having little to no constraints - begins to reveal its own and highly idiosyncratic architectural tectonics and narratives.

\section{A PRINTING-ECOLOGY: ADDITIVE MANUFACTURING ACROSS THE AMERICAS}

There are various advantages to printing with local earth, soil and recycled concrete. Buildings are sourced and situated within their context and can take full advantage of the method's diverse ecological and environmental benefits such as cheap construction, CO2 neutral material acquisition, reduced transportation, and the creation of new distributed economic models based on localized industry. In recent building experiments, soil has been mixed and hybridized with concrete to further improve its material properties, 
making it more durable and meeting the needs of today's building codes.

Based on a rich variety of vernacular earth construction precedents across the Americas, we believe that there are real opportunities for marrying ancient knowledge with modern technology. The need to move towards a thorough exploration of industrialized building processes is a result of the rapid increase for housing and other building types globally. Automation is a key factor to contribute to pressing architectural and urban questions regarding globalization. It allows for mass-customization and can help to overcome the modern paradigm of self-similar and repetitive mass production which poses a particular problem in urbanism and is a result of the limits of the fabrication technology. Additive manufacturing is a new building technology that has to question current assumptions regarding history, precedent, material usage, ecology, and environment. The re-definition of a building process is a unique opportunity to have an impact on global anthropogenic mechanisms.

There is a vast future potential to re-visit a shared successful history of soil construction across the Americas and marry it with automated construction processes in light of new technological developments. It is part of the nature of doing architecture that we all ask ourselves - 3D printed or not - what is today's Casa Grande (translated here as The Great House)? What is the house that is able to take into account global ecological and environmental concerns, questions current economic models and modes of production, creates comfortable living conditions, is affordable, flexible, expands architectural narratives, creates remarkable spaces for habitation, and pushes the boundaries of the discipline? This paper argues that it might well be a soon to be constructed $3 \mathrm{~d}$ printed piece of architecture.

\section{ENDNOTES}

1. "About," RepRap Wiki, accessed July 21, 2016, http://reprap.org/wiki/About

2. See patents held by University of Southern California and Behrokh Khoshnevis for the Contour Crafting project, "Contour Crafting - Robotic Construction System," Contour Crafting, accessed July 25, 2016, http://www.contourcrafting.org/

3. Hod Lipson and Melba Kurman, Fabricated: The New World of 3D Printing (Indianapolis: Wiley, 2013)

4. "Dubai: $25 \%$ buildings to be 3D printed by 2030, , accessed July 21, 2016, http://www.constructionweekonline.com/ article-38750-dubai-25-buildings-to-be-3d-printed-by-2030/

5. T.T. Le et al., "Mix Design and Fresh Properties for High-performance Printing Concrete," Materials and Structures 45 (2012): 1221-1232.

6. "Environmental Impact of Concrete," Wikipedia, accessed July 21, 2016,

7. "The Deadly Global War for Sand," Wired, accessed July 21, 2016, http://www. wired.com/2015/03/illegal-sand-mining/
8. "TU Eindhoven Helps Builders Pioneer Recyclable Concrete Constructions with Giant 3D Printer," Designboom, accessed July 21, 2016, http://www.designboom. com/technology/tu-eindhoven-concrete-3d-printer-06-28-2016/

9. In 2016, a studio led by Sasa Zivkovic at Cornell University constructed a large scale open source 3d printer called Daedalus. Costing roughly $\$ 7000$, its blueprints will soon be made available on an open source platform on the Cornell AAP website: http://aap.cornell.edu/

10. "NASA Awards Top Three Design Finalists in 3-D Printed Habitat Challenge," NASA, accessed July 22, 2016, http://www.nasa.gov/directorates/spacetech/centennial_challenges/3DPHab/2015winners.html

11. Ronald Rael, Earth Architecture (New York: Princeton Architectural Press, 2009), 9-10.

12. Marcel Vellinga et al, Atlas of Vernacular Architecture of the World(Routledge, 2008) 11.

13. See for example the Musgum mud dwellings in Cameroon which are formed based on a catenary arch, an optimal form for load distribution in compressive structures."Musgum Mud Huts," Wikipedia, accessed July 25, 2016, https:// en.wikipedia.org/wiki/Musgum_mud_huts

14. “Huápoca," Wikipedia, accessed July 25, 2016, https://en.wikipedia.org/wiki/ Hu\%C3\%A1poca

15. "The Science of Playing in the Mud," Archaeology Southwest, accessed June 23, 2016, https://www.archaeologysouthwest.org/2014/07/24/ thescienceofplayinginthemud/

16. Vint and Associates Architects Inc. for the U.S. Department of Housing and Urban Development, Office of Policy Development and Research, Southwest Housing Traditions: Design, Materials, Performance (2005), https://www.huduser.gov/ portal//Publications/pdf/SouthwestHousing/SW_Housing_Traditions.pdf, 41-44.

17. “Casas Grandes," Wikipedia, accessed July 26, 2016, https://en.wikipedia.org/wiki/ Casas_Grandes

18. "Minibuilders," Institute for Advanced Architecture Catalonia, accessed July 26, 2016, https://iaac.net/research-projects/large-scale-3d-printing/minibuilders/

19. Gernot Minke, Building with Earth: Design and Technology of a Sustainable Architecture (Basel: Birkhäuser - Publishers for Architecture, 2006) 50.

20. Horst Schroeder, Sustainable Building with Earth (Springer International Publishing, 2016) 9-10.

21. "Contour Crafting - Robotic Construction System," Contour Crafting, accessed July 25, 2016, http://www.contourcrafting.org/

22. "Home," WinSun, accessed July 25, 2016, http://www.yhbm.com

23. "Earth Architecture Education \& Disaster Relief," California Institute of Earth Art and Architecture, accessed July 25, 2016, http://calearth.org/

24. “Let's print together the first adobe building !!," WASP World's Advanced Saving Project, accessed July 25, 2016, http://www.wasproject.it/w/en/ stampiamo-insieme-la-prima-casa-di-terra/

25. Gernot Minke, Building with Earth: Design and Technology of a Sustainable Architecture (Basel: Birkhäuser - Publishers for Architecture, 2006) 80-82.

26. Mariana Correia, editor et al, Vernacular Heritage and Earthen Architecture(CRC Press, 2013) 61.

27. "Mesh Mould," Gramazio Koehler Research, accessed July 25, 2016, http://gramaziokohler.arch.ethz.ch/web/e/forschung/221.html

28. "About," Branch Technology, accessed July 25, 2016, http://www.branch. technology/

29. HANNAH is an architecture office based in the US and Germany that investigates automated building processes and their implications on architecture. It was co-founded by Alexander Chmarin, Alexander Graf, Leslie Lok, and Sasa Zivkovic. "Projects," HANNAH Architecture \& Design, accessed July 25, 2016, http://hannahoffice.org/?/Projects/ 